\title{
Research on the Development of Regional Visual Design in Northern Shaanxi
}

\author{
Chunhua Jia \\ Art Institute, Yulin University, Yulin, Shaanxi, China \\ 317950860@qq.com
}

\begin{abstract}
Keywords: Modern design; Folk paper cutting; Design modeling language; Traditional culture absorption and reference; Regional design
\end{abstract}

\begin{abstract}
The art of paper cutting is highly generalized and highly concise in conformity with the needs of modern design and modeling language. Therefore, the contemporary design can be extracted from the folk paper-cut art with a strong Chinese style, after a high degree of abstract deformation, to find the simple and clear visual characteristics of the modeling elements, and to inject new meaning to the tradition. Adapt ancient forms for the ancient serve the present. Besides, after the historical precipitation, the paper cutting theme can also provide a wealth of material for modern design database.
\end{abstract}

\section{Introduction}

The rapid development of industrial civilization and the trend of global economic integration have gradually formed the erosion of the weak culture by a strong culture. The world seems to be developing towards an economic way, a material way and a value concept, which has led to the neglect of the values of different nationalities, cultures and different ecological values. However, this trend of development can not solve the spiritual problems of human harmonious survival. In view of modern people's thinking mode and human nature, how to make a more thorough and systematic study of traditional culture and how to learn and absorb the essence of traditional culture for re creation has become more and more serious thinking and deepening of the current generation of graphic designers and be a topic to be discussed.[1,2,3]

Regional culture refers to the common way people in a certain region are in the aspects of behavior, language, religion, customs, etc., mainly in the differences in administrative division, geographical location, terrain climate and distribution of natural resources, as well as the differences in living customs and consumption characteristics. Regional culture based regional design will also be determined. [4,5] The characteristics of local culture and economic development are reflected in the display and communication of the design, so as to lay a distinct characteristic for the regional culture. As the root of regional design, it must be based on the national culture. The folk paper-cut in Northern Shaanxi contains rich historical culture and ancient Chinese philosophy. The important role of the development of folk paper cutting in regional design is not only to inherit folk traditional paper-cut patterns, but also to lay a deep cultural foundation for the development of the regional design. [6,7]

\section{Regional Visual Design should Extract Design Elements from Folk Culture}

Modern design is not only from the high summary of paper cutting art, highly concise modeling language, composition and rich themes to find inspiration, so that the design elements through the height of purification, search for simple and clear visual features, but also from other folk culture to find the root of the design. Design is a people-oriented activity. It has no borders and no language barriers. Good design relies on modeling to convey information. Modern design language requires easy identification and easy memory. [8]

The art of paper cutting is highly generalized and highly concise in conformity with the needs of modern design and modeling language. Therefore, the contemporary design can be extracted from 
the folk paper-cut art with a strong Chinese style, after a high degree of abstract deformation, to find the simple and clear visual characteristics of the modeling elements, and to inject new meaning to the tradition. [9,10]Adapt ancient forms for the ancient serve the present. Besides, after the historical precipitation, the paper cutting theme can also provide a wealth of material for modern design database. The folk paper-cut art, due to the limitations of the performance tools and materials, is mainly embodied in the expressive characteristics of generalizations, exaggerations, simplicity, rough and rich and so on. It can not take naturalistic realism, but the two processing, combination, decoration and induction of the image by the paper-cut artists themselves, after their own observation, analysis and imagination. The pattern is mostly an image, non realistic, and rich life style, with the inner essence of the perfect, beautiful, beautiful, beautiful and harmonious art, which is also an important part of Chinese art thinking.

Chinese traditional folk paper-cut art embodies the typical primary way of thinking. This kind of thinking is a natural way of visual perception without professional training. It embodies the traditional aesthetic ideal of China: "harmony between man and nature", "environment and image". It is not mechanical replication of natural objects, but full of cognition and ideology, and the purpose of grasping the overall structure of objects. When the traditional folk paper-cut artists convert their visual feelings into symbolic images, they are not restricted by the time and space of the moment and are not restricted by the visual viewpoint, but are rearranged and constructed in accordance with the author's original visual cognition of the object and in accordance with the inner wishes and self ideals. Visual form, making it rationalized, effectively eliminates the conflict between reality and ideal, the imbalance between the subject and the object, and adjusts the contradictions between the main culture and instinct, the rationality and the sensibility, the society and the individual.

\section{The Enlightenment of other Folk Art in Northern Shaanxi on Visual Design}

As a form of folk culture, paper-cut in Northern Shaanxi provides a good design theme for the Northern Shaanxi regional design. In the same way, the folk culture of Northern Shaanxi is rich and varied. It is an important part of the Northern Shaanxi culture. It mainly includes farmers' painting, not, weekly living, puppet, cloth pile painting, clay sculpture, clothing and so on. These aspects are not only closely related to paper-cut, but also the material source of regional design in the wood area. Such as the paintings by farmers in Northern Shaanxi, such as "blowing hands", "cutting millet", "cattle" and so on, the experts at home and abroad, both inside and outside the prison, once agreed that it was "folk modern art", and on this basis put forward the conclusion of "folk modern Bian Yi". It maintains the original nature of Shi duo, and is close to the real material production of Japanese tongue, with distinct utilitarian significance. This is the so-called folk art or farmer painting. Material and spiritual, aesthetic and practical in many works, achieve perfect unity. It has historically formed a materialized form of folklore, and it is interdependent with folklore, conveying the emotion of modern people's lives.

The folk culture of Northern Shaanxi is also very rich in theme, including flower and bird, fish worm, animal and fruit, mythology, folklore, legend, opera characters, utensils, primitive totem, symbols and auspicious characters, which can be said to be a complete set of Chinese traditional arts and crafts. Contemporary designers can draw inspiration from them and design more updated and more expressive works of excellence.

\section{Regional Folk Art Theme is the Source of Regional Visual Design}

Folk art lays an important foundation of national psychology, or the basis of aesthetic perception. As a kind of plastic arts, modeling is varied and colorful, with unique aesthetic thinking and simple ideology. Paper cutting is a wonderful work of Northern Shaanxi folk art, which has enriched the Northern Shaanxi culture and local people's life beliefs. From the fundamental nature of the folk art, it is only the change in the form of display, all of which are the recipients of the inheriting of the original culture. Many traditional folk arts have a close relationship with the witchcraft, the 
primitive religion, the mythology and the belief, and so on. Most of them have a long history of development and merge with the orthodox in the process of development. And the influence of external culture gradually removed or reduced the utilitarian color. The shaping and many storylines of Northern Shaanxi have common spiritual purposes and uses with other categories of folk art.

The paper cut paper in Northern Shaanxi, with its own distinctive features, provides a cultural vein for the design of regional design, and also provides excellent design elements for regional design. It is an excellent representative of other folk art in the regional design. The outstanding elements of these folk arts have become a part of the modern designer's creative system, and can better reflect the essence of national cultural characteristics and regional design in the design works. At present, China's modern design has gradually shown the style of Chinese design, but the national culture of our country is huge and different, which provides an opportunity for the development of pluralistic design in the nation. The regional design of our country should highlight the characteristics of national culture, so we must learn from the regional folk art.

\section{The Development of Modern Regional Design should Seek Regional Characteristic Culture}

The development of modern regional design is an important part of regional economic development, reflecting the life style of the people in the region. It is an important way of expression of regional culture and a pillar of regional cultural development. Since the beginning of the century, our country's design has been studying the design education system represented by the Bauhaus Institute of design and the Institute of plastic arts in Ulm, which has lost the opportunity and vitality of our traditional technology. The design of our country in the 80s lost its national character, and the blind eye followed the Western functionalism and its constructivism. The grid, as well as the point, line, and surface design form reference. In this period, the modern design of our country follows the direction of the world design in theory and practice, and strives to be in line with the international design. To a certain extent, it lays a foundation for the modernization of our country. The problem is that with the development of the economy, the design features of our country are not clear, and the international style of the modern metropolis is helpless. . Therefore, building the design with Chinese national characteristics has become an inevitable trend in the new era.

\section{Conclusion}

Use modern regional design themes to provide designers with more design space. From the vivid, free and interesting artistic forms of folk art, the pursuit of novel visual language, modeling elements and artistic forms can better accumulate rich resources for the design of nationalization in China, and play a positive role in the healthy development and diversification of regional design. For example, Jingcheng automobile advertisement, combined with the image of paper cutting and automobile, is novel and innovative, and has the characteristics of Chinese design. It is concise and clear, and has a profound meaning.

\section{References}

[1] Thoughts on the introduction of paper-cut art to modern urban design culture [J]. Fan Yaling, Liu Jianli. Journal of Yunnan Normal University (NATURAL SCIENCE). 2009 (05) (in Chinese)

[2] Discussion on regional culture in product design [J]. Lu Qing, Zhang Chen. Art education. 2009 (03) (in Chinese)

[3] Analysis of the application of paper-cut art in modern art design [J]. Lu Hua. Journal of Fujian Normal University Fuqing branch. 2009 (01) (in Chinese)

[4] The theme and cultural implication of the paper cutting in Northern Shaanxi [J]. Wang Jie. Popular literature and art (Theory). 2008 (12) (in Chinese)

[5] Cultural implication of traditional Chinese graphic arts [J]. Huang yzhu. Journal of Chaohu College 2002 (02) (in Chinese) 
[6] Chinese folk paper-cut vertical and horizontal view [J]. left Hanzhoung. Search for roots. 1995 (04) (in Chinese)

[7] Enlightenment of folk paper-cut art to modern graphic design [D]. Ma Li Jiangnan University 2008(in Chinese)

[8] Shaanxi folk paper-cut innovation and Application Research [D]. Wang Bei. Beijing Forestry University 2007(in Chinese)

[9] Design art ten lecture [M]. Shandong Pictorial Publishing House, Zhuge armor, 2006(in Chinese)

[10] The history of Chinese art and design [M]. Shaanxi people's fine arts publishing house, Zhao Nong, 2004 (in Chinese) 